\title{
Study on Electricity Price Formation Mechanism Based on the Renewable Energy Power Generation with the Externalities of Grid Connection
}

\author{
Qiang Cai \\ Sichuan Radio and TV University, Chengdu, 610041, China
}

Keywords: Renewable energy, Externalities of grid connection, Electricity price formation mechanism

\begin{abstract}
In nowadays society, the promotion of conservation and environmental protection has been firmly established, which includes energy use. People continue to advocate for renewable energy, which makes the development speed of renewable energy has been greatly improved. Intermittent renewable energy development has also brought new challenges for power system planning, safety, design and operations. In the past development, aiming at how the grid connection of intermittent renewable energy generation participate in electricity market operation problems, many domestic scholars have done the corresponding research work, especially in terms of electricity price formation mechanism. In this paper, it fully describes the development process of renewable energy development participating in the competitions of electricity markets, describes the research results of electricity price formation price of renewable energy power generation in various countries at home and abroad, and analyzes the impacts of renewable energy power generation on the market electricity price when participating in the electricity market operations.
\end{abstract}

\section{Introduction}

The development of renewable energy power generation enables the optimization of energy structure, reduce the emissions of greenhouse gas, and achieve the sustainable development of energy, and this issue has been concerned by all countries in the world. In the development of science ad technology, the power generation technology of renewable energy continues to develop, such as: wind energy, solar energy, etc., and such kind of power generation has gradually increased its penetration in the power system.

\section{Ideas and introductions of the externalities of grid connection}

The founder of "Cambridge School" Marshall proposed "External Economy" and "Internal Economy" in 1890, and from then on, it opened a precedent example for the theoretical research of externality; after that, the founder of Welfare Economy Pigou proposed the concepts of private marginal cost, marginal social net value and "Pigovian tax"; the theory of externality has become a hot research subject for modern economics; therefore, there is a larger development on the studies, such as internalization of grid connection externalities, methods of internalization and dynamic externalities [1].

\section{Formation mechanism of electricity price}

With the development in recent years, many countries have developed appropriate future development plans and incentive policies for the grid connection externalities for the renewable energy power generation, and also have explored the adaptation of renewable energy power generation towards the mechanism of electricity market. At present, it obtained two types of policies: coerciveness and voluntary. Coerciveness is formulated by the government through laws and regulations, which includes the following three categories: 
1). The feed-in tariffs of the related enterprises for the renewable energy power generation will be given the appropriate support from the government, so it is called feed-in tariffs system;

2). Conducting open bid inviting for the project developers of renewable energy power generation, so it is called competitive-bidding system;

3). Laws and regulations stipulate the occupied proportion of the renewable energy power generation in the power supply, and relying on the market to promote the effective development of renewable energy, so it is called Portfolio Standard or Renew-able Energy Certificates System.

Voluntary policies are not regulated by laws and regulations, mainly purchasing the renewable energy voluntarily relying on the electricity consumers, so that to promote the development of renewable energy power generation.

\section{Feed-in tariffs mechanism}

Feed-in tariffs mechanism develops the feed-in tariffs through the government departments, and stipulates the purchasing obligations of power supply enterprises towards renewable energy power generation, so that to ensure the daily steady incomes of renewable energy power generation enterprises. This approach can also be called as mandatory purchase method. The level of feed-in tariffs for the renewable energy power generation can be confirmed by two kinds of basic methods, one is standard cost method; the other is opportunity cost method. The standard cost method is based on the level and scale of renewable energy power generation technologies to determine whether it is purchased by a reasonable price; opportunity cost method is constructed on the basis of electricity market bidding, and the government gives the corresponding price subsidies. In order to promote the development of renewable energy, the feed-in tariffs system can be stimulated through two ways, namely are administrative way and economic way, and many countries in Europe will adopt this approach, in which the fixed fee-in tariffs system in Germany and the premium price system are most representative.

\section{Electricity price system in Germany}

The fixed feed-in tariffs system is developed in accordance with the standard cost method, and each on-grid price of renewable energy power generation is determined by the government, so the power grid enterprises should pay the corresponding fees to the renewable energy power generation enterprises strictly according to the prices developed by the government.

Electricity price system in Spain

Premium price system is formulated by combining the standard cost method and opportunity coast method, which considers not only the actual cost generated from the renewable energy power generation, but also the electricity bidding in the market. When this method operates, it needs to develop corresponding principles for the price of renewable energy power generation: it must be based on the price when selling the conventional power generation technologies, and be based on the multiply of the appropriate proportionality coefficients; and also can add the electricity price of the government's fixed subsidies based on the floating price in the market. Premium price system not only encourages the competition between the renewable energy power generation and electricity market, but also guarantees the price of renewable energy power generation [2].

\section{Competitive-bidding system}

The competitive bidding system of renewable energy power generation refers on the basis of ensuring the renewable energy can surf the Internet, the government calls for bids on the projects of renewable energy power generation, and signs a long-term power purchase contract with its power generation suppliers. In ensuring the access to the Internet, the declared price in the project tends to be the main factors affecting the evaluation, and this is also known as the competitive-bidding price system. The implementation of the competitive-bidding system will produce a lot of advantages and disadvantages, and these are the conclusions based on the bidding companies:

Advantages: (1) By bidding between companies, it will greatly reduce the price of renewable energy power generation; (2) The government uniformly publish the bidding project, which greatly contributes to the development of diversified power generation technology types; (3) Signing a long-term contract between the government can effectively provide a income guarantee for investors, 
and to some extent, it is conducive to the development of new technologies, so that to obtain greater profits.

Disadvantages: (1) The process time for evaluating the project is too long, the requirements for investors in the early stage are too high, and the pre-investment is also too great; (2) Due to the contract time is very long, it is very difficult to calculate the cost required by the renewable energy power generation technologies, and very difficult to master the change of cost required.

\section{Portfolio Standard}

Renewable Portfolio Standard, RPS stipulates the proportion of renewable energy power generation in the total electric energy through the legal behaviors, and its proportion will be shared by various electricity suppliers and electricity sellers. Portfolio Standard will usually come with a green trade link - Renew-able Energy Certificates, RECs, and this part is known as Renew-able Energy Certificates system. The government will not invest too much money and management, which is a policy model fully based on the market, and from which the power supplier will complete the government-mandated quotas through the method sought in the market. Among them, the Portfolio Standard has its advantages and disadvantages:

Advantages: (1) The investors can increase the confidence of renewable energy power generation project through long-term development goals and the mandatory quotas from the government; (2) There is no need for the government to manipulate the market, which greatly reduces the management cost of the government; (3) Trading method of Renew-able Energy Certificates is combined with the traditional power generation auction market, which can effectively make the renewable energy project reflect its external values, makes the electricity market have a fair competitive environment, so that to make the renewable energy power generation has possible competition with other power generation companies.

Disadvantages: (1) The establishment of the Portfolio Standard, to some extent, will restrain the development of renewable energies, and if the development speed of renewable energy power generation increases, it will go far behind the goal of policies, which will lead to the serious decline of price when trading the Renew-able Energy Certificates, but the price is also as the subsidies for new energy companies; (2) Due to the instability of market competition, it will seriously affect the price of renewable energy power generation; (3) Market mechanism will lead to some enterprises and areas with advantages form the monopolies in the competition; (4) The goals of Portfolio Standard and the trading system of Renew-able Energy Certificates are very complex in terms of design, and under the competition of electricity market, it is very difficult to make accurate predictions.

\section{Green Electricity Price System}

Green Electricity Price System encourages the users to voluntarily purchase the electricity generated from the renewable energy power generation with the extra costs, so that to correspondingly relieve the cost investment of renewable energy power generation. When the users purchasing the renewable energies, there are corresponding measures to certificate the electricity purchased by users, which fully ensures that the purchased cost is used for the power generation of renewable energies. Increasing the investment of renewable energy power generation through users' choice, but the increase in investment ultimately depends on the related recognition degree of users on renewable energies.

The government will develop mandatory development policy, and add the voluntary principles on the basis of mandatory. Using this policy will attract the users with the sense of responsibility to use voluntarily bear the cost used for the renewable energy power generation, so that to achieve the commitment to the development of renewable energy power generation. Green electricity price system also has its advantages and disadvantages:

Advantages: (1) Electricity users use extra money to purchase the electricity generated by the renewable energies, which fully reflects its support and social responsibilities for the renewable energy development; (2) There are corresponding policies from the government, so it is simple and clear when operating; 
Disadvantages: Voluntarily purchasing electricity will lead to a lack of support, so that to see the future clear goals of renewable energy development; (2) The costs for the different electricity companies used for renewable energy power generation are different, which will seriously cause the instability of green electricity price; therefore, it will lead to the users are more willing to buy electricity from cheaper electricity companies, which is not conducive to the development of renewable energies ${ }^{[3]}$.

\section{Conclusion of the foreign electricity price formation mechanism}

Developing a corresponding mechanism of renewable energy power generation, which can effectively reduce the risks of renewable energy power generation undertaken by the investors, thus is able to improve the social benefits of renewable energy power generation. The formation of many foreign electricity price mechanisms is in the process of studying the renewable energy power generation, and the basis of formation is mostly through the law. When developing, it has clear objectives, resources and technologies, as well as government policies and tax subsidies, which provide effective supporting measures for the electricity price formation mechanism of renewable energy power generation.

\section{China should implement policy recommendations}

The electricity price systems in many foreign countries are promoting, but many foreign lessons tell us, the improper formulation of electricity price will not only stop the development of renewable energy power generation, but also produce reverse actions, The management and implementation of electricity price system are very simple, and as long as protecting the diversification of resources and local industries, it is able to achieve a very good development. Through the electricity price system in the above countries, our electricity purchasing law needs to do more detailed researches.

If the electricity market is still in its infancy, the time costed by the electricity purchasing law is shorter than that of Renewable Portfolio Standard. China has developed a basic electricity purchasing law - wind electricity price as the cost and reasonable profits. Through the analysis on the electricity price system in foreign countries, the cost for our country to implement electricity purchasing law and management is the lowest; however, in order to be able to sufficiently reduce the cost of charging the returned energy charge, it should work out the maximum amount corresponded to the cost ${ }^{[4]}$.

For the existing electricity purchasing law and policy is not from the same department, it leads to the investors and suppliers can not deal with it, and directly affects the development of power industry and the implementation of government policies. China's "sharing the parts that the wind electricity on-grid price is higher than the average electricity price" has led to the emergence of many problems. The decision for the National Electric Power Department to regulate "sharing the parts that higher than the price" does not clearly specify how to share and the range of share, which directly leads to the policy of National Electric Power Department can not be achieved. It also leads to the situation that "who construct the wind electricity plants who take the responsibility", makes it difficult to digest the electricity price in the grid, and leads to bring the economic losses to some regions with good wind electricity resources and larger development potentials.

The level of on-grid price will have a direct impact on the enthusiasm of investors, operators and users on the electricity price. Under normal circumstances, the introduction of relevant policies are generally not allowed to modify, but in order to sufficiently reduce its cost, and to encourage its development and competition, it can make appropriate adjustments and improvements on the on-grid price policy. The key of electricity purchasing law is to determine the different electricity prices due to the different types of renewable energy power generation under different technologies and different installed capacities ${ }^{[5]}$.

China should rely on the electricity purchasing law to promote the external career development of grid connection of renewable energy power generation, to fully absorb the foreign experience, and to establish the electricity price mechanism perfectly suited our own country, so that to promote the development and progress of China's power industry. 


\section{Conclusion}

In this paper, through the related experience from various countries, it concludes that comparing to the traditional power generation, the renewable energy power generation has reduced the cost of power generation, but the input cost for renewable energy power generation is higher, thus leading to the renewable energy power generation is difficult to compete with the traditional power generation; therefore, the development of renewable energy still needs to be supported by the related policies from the government. The continuous development of science and technology also makes the power generation technologies of renewable energy improved, so that the problems of its competition produced in the electricity market become more and more obvious. In this paper, it studies various foreign electricity price systems and the competition participated in the electricity market, and fully analyzes the impacts of renewable energy power generation on the electricity market. Therefore, it provides the corresponding experience for our grid connection externalities of the renewable energy power generation, and finds a new way for the grid connection externalities of the renewable energy power generation from foreign experience.

\section{Acknowledgments}

This paper is the National Natural Science Foundation of China: "Study on the Formation Mechanism of Renewable Energy Electricity Price Mechanism” (ID: 71473031).

\section{References}

[1] Chen Zheng, Yang Jiajia, Jin Xiaoming, et al. A literature survey for pricing mechanisms and bidding strategies of renewable energy generation. Journal of North China Electric Power University (Natural Science Edition), 2014, 41(2):89-98,102.

[2] Zhao Erdong, Liu Pingkuo. Policy Effects of Feed-in Tariff and Tradable Green Certificate—Based on the Development of Biomass Power Industry in China. Industrial Technology \& Economy, 2013, (9):125-137.

[3] Fu Liwen. Analysis on the Economic Externalities of Grid Connection of Clean Energy Power Generation and Study of Electricity Price Formation Mechanism. North China Electric Power University (Beijing), 2012

[4] Fan Bin. Methods and Applied Research of Electricity Price Regulation. North China Electric Power University (Beijing), 2010.

[5] Ma Xiangdong. Grid Connection of Renewable Energy Power Generation and the Impacts of Smart Power Grids on Power Supply Marketing. North China Electric Power University (Beijing), 2011. 